\title{
EL MITO DE ALCESTIS EN LA LITERATURA LATINA: EL CASO DEL CENTÓN
}

\author{
Marcos Carmignani ${ }^{1}$
}

\begin{abstract}
Resumo
En este artículo, nos ocuparemos del centón mitológico de Alcesta, poema anónimo de 162 versos (AL 15 Riese2) que narra el mito de Alcestis y Admeto, ya tratado en la famosa tragedia de Eurípides. Nuestro objetivo central es analizar la función que cumplen los versos virgilianos reutilizados en este centón y su doble relación tanto con la tradición mítica grecolatina de Alcestis como con el propio contexto de origen o fuente, es decir, el texto virgiliano, específicamente, la Eneida. Como veremos, dicha resignificación constituye una relectura no sólo de los versos virgilianos sino también del propio mito. Pero antes de comenzar con el análisis, haremos una breve historia del mito de Alcestis tal como aparece en la literatura grecolatina -con especial atención a lo que ocurre en el mundo romano- de tal modo que sirva de telón de fondo para poder comprender más cabalmente el tratamiento que se hace del mito en el centón virgiliano.
\end{abstract}

Palavras-chave: Centón; Alcestis; Mito; Virgilio; Intertextualidad.

\begin{abstract}
In this paper, I will deal with the mythological cento Alcesta, an anonymous 162 lines poem (AL 15 Riese $^{2}$ ) which retells the myth of Alcestis and Admetus, already treated in the famous tragedy of Euripides. My aim is to analyze the function of the reused Virgilian lines and its double relation both to the Greco-Roman mythical tradition of Alcestis and to the original context of the main source, i.e., the Aeneid. As I will show, the resignification of these lines represents a re-reading not only of the Virgilian epic but also of the myth. Before beginning with the analysis, I will do a brief summary of the myth of Alcestis as it appears in GrecoRoman literature - with special attention to the Roman world - so to understand the treatment of the myth in this Virgilian cento.
\end{abstract}

Keywords: Cento; Alcestis; Myth; Virgil; Intertextuality.

\footnotetext{
1 Profesor Titular de Filología Latina y de Historia de la Literatura Latina en la Universidad Nacional de Córdoba. Investigador del CONICET. Fue becario de la Scuola Normale Superiore di Pisa, bajo la dirección de Gian Biagio Conte. Se especializa en novela latina y en los centones virgilianos.
} 


\section{INTRODUCCIÓN}

En el campo de la literatura tardoantigua abundan las rarezas. No es extraño que la filología clásica haya desdeñado esas obras menores frente a los monumentos literarios de la edad de Augusto. Sin embargo, en algunos de esos textos de menor trascendencia literaria es posible encontrar un buen número de argumentos como para revisar ese desdén y descubrir, detrás de un prejuicio muchas veces acertado, obras de un interesante valor literario. Este es el caso de los centones virgilianos.

El término centón proviene del griego $\kappa \varepsilon \dot{v} \tau \rho \omega v$-que originalmente significaba un manto muy humilde, hecho de retazos, que se ponía sobre el lomo de un burro- y alude, en literatura, a un texto poético original formado por versos o partes de versos de poetas célebres, sobre todo de Homero y Virgilio ${ }^{2}$. El origen del género se remonta al mundo griego, por ejemplo, a la parodia a Homero realizada por Hiponacte o Hegemón de Tasos, aunque no forman un continuum de partes homéricas. En el mundo latino, se pueden definir como etapa protocentonaria los textos del Culex, Ciris y Satyricon 132.1, siempre con Virgilio como fuente. Nos han llegado dieciséis centones virgilianos, desde el 200 hasta cerca del 534. De ellos, doce son de tipo mitológico o de argumento secular y cuatro contienen material cristiano. Asimismo, doce se conservan en la llamada Anthologia Latina, una compilación de versos realizada en África, quizá en el siglo VI, que comprende principalmente poetas africanos de la latinidad tardía. El testimonio principal y más antiguo de la $A L$ es el codex Salmasianus, descubierto por el humanista francés Claude Saumaise (1588-1653), conservado actualmente en París como Parisinus 10318 y datado entre los siglos VIII y IX ${ }^{3}$.

En este artículo, nos ocuparemos del centón mitológico de Alcesta, poema anónimo de 162 versos ( $A L 15$ Riese $^{2}$ ) que narra el mito de Alcestis y Admeto, ya tratado en la famosa tragedia de Eurípides. Nuestro objetivo central es analizar la función que cumplen los versos virgilianos reutilizados en este centón y su doble relación tanto con la tradición mítica grecolatina de Alcestis como con el propio contexto de origen o fuente, es decir, el texto virgiliano, específicamente, la Eneida. Como veremos, dicha resignificación constituye una relectura no sólo de los versos virgilianos sino también del propio mito. Pero antes de comenzar con el

\footnotetext{
2 Estudios indispensables para entender la tipología del centón son los de LAMACCHIA (1985), POLARA (1990), SALANITRO (1997) y McGILL (2005). Además, son dignos de consideración las introducciones a las ediciones de los centones que se vienen publicando desde la década de 1980.

${ }^{3}$ Esta compilación es objeto de estudio, desde 2010, de la revista AL. Rivista di studi di Anthologia Latina, editada por L. Zurli.
} 
análisis, haremos una breve historia del mito de Alcestis tal como aparece en la literatura grecolatina -con especial atención a lo que ocurre en el mundo romano- de tal modo que sirva de telón de fondo para poder comprender más cabalmente el tratamiento que se hace del mito en el centón virgiliano.

\section{ALCESTIS Y SUS DIVERSAS CARAS EN LA LITERATURA GRECOLATINA}

En el artículo del $O C D$, Dowden (2000) resume con precisión el mito: Alcestis era hija de Pelias y esposa de Admeto, rey de Feras (Tesalia). Pelias dispuso que quien pudiera uncir un león y un jabalí a un carro podría desposar a su hija Alcestis. Admeto, con la ayuda de su amante Apolo, logra la proeza, pero olvida hacerle un sacrificio a Artemisa, por lo que encuentra su lecho nupcial lleno de serpientes. Siguiendo el consejo de Apolo, aplaca a la diosa y obtiene de las Moiras la recompensa de que alguien pudiera morir en su lugar, pero sólo Alcestis se ofrece a hacerlo. Hay dos versiones sobre la vuelta a la vida de Alcestis: Perséfone la envía al reino de los vivos o Heracles, luego de luchar con Thánatos, la rescata. La inmolación de Alcestis tiene rastros del sati o satí, el rito hindú en el que una mujer se inmola en la pira funeraria del marido recién fallecido. La palabra se origina en la leyenda de la diosa Sati, esposa del dios Shiva: el rito constituía un acto de devoción hacia el marido y sólo las mujeres virtuosas podían cumplirlo. Asimismo, la muerte de Alcestis se vincula con una serie de funciones del folk-tale: 1) un hombre joven enfrenta a la muerte, 2) su salvación sólo puede producirse si otro muere en su lugar, 3) sólo su esposa se ofrece, 4) una divinidad le garantiza a la esposa el regreso a la vida.

En el mundo griego, como se sabe, el tratamiento más conocido del mito se lo debemos a la tragedia homónima de Eurípides, texto con el que el centón presenta, como veremos, una serie de variantes. Sin embargo, Paolucci $(2014)^{4}$ cita no menos de veinte autores y obras donde el mito es mencionado de una u otra manera, desde Homero hasta el paremiógrafo del siglo II Zenobio, pasando por autores como Hesíodo, Esquilo, Sófocles, Platón, Calímaco, Apolodoro y Plutarco.

Por su parte, en el mundo romano, la presencia del mito se hace aún más densa, incluso con la particularidad de que nos han llegado dos composiciones tardoantiguas completamente dedicadas al mito de Alcestis y Admeto: la Alcestis Barcinonensis y la Alcesta centonaria. Dicha tradición comienza con las obras fragmentarias de Accio y Levio. Del

\footnotetext{
${ }^{4}$ Para esta sección, nos valemos del excelente resumen ofrecido por Paolucci (2014a).
} 
primero, se conserva un solo verso de su drama Alcestis; del segundo, algunos pocos fragmentos del drama del mismo nombre, pero que podrían ser suficientes como para postular que fue Levio quien innovó la versión de Eurípides al quitar la figura de Heracles -que estaba presente en Accio- para darle a la historia un aspecto más marcadamente sentimental. La lista de alusiones al mito continúa con la obra de los poetas elegíacos (Tibulo, "Lygdamus", Propercio y Ovidio), de los que rescatamos el comienzo del libro III del Ars amandi ovidiano, con su elogio a las mujeres, donde dice "Dejad ya de hacer extensivo a todas el delito de unas pocas; que cada mujer sea valorada según sus méritos individuales" (parcite paucarum diffundere crimen in omnes / spectetur meritis quaeque puella suis, 3.9-10). Así, los malos ejemplos de Helena, Clitemnestra y Erifile deben ser opuestos a las virtuosas Penélope, Laodamía, Evadne y Alcestis, de quien el poeta dice en un dístico: "la esposa de Págasa redimió de su destino al Feretíada, y en el funeral del marido y en lugar suyo fue llevada a enterrar la esposa" (fata Pheretiadae coniunx Pagasaea redemit: / proque viro est uxor funere lata viri, 3.19-20). Este carácter ejemplar de Alcestis permeará las apariciones del mito en la literatura latina (Culex, Valerio Máximo, Marcial, Estacio, Juvenal y Sidonio Apolinar) y en la poesía sepulcral $(C L E)$. Algunas excepciones son las alusiones al motivo de la servidumbre de Apolo en favor de Admeto, que aparecen en Séneca, Lucano y Valerio Flaco, y el tratamiento que realiza Draconcio en su De raptu Helenae (Rom. 8.206-210), donde Alcestis es caracterizada de manera caricaturesca como una exigente ama de casa. Del mundo escolástico, por su parte, derivan algunas alusiones al mito para aclarar la influencia de Eurípides en Virgilio, con respecto a la interpretación del famoso pasaje de Aen. 4.698-9, referido al corte del cabello de Dido: de este modo, Servio y Macrobio explican que este motivo deriva de los vv. 73-76 de la Alcestis de Eurípides. En este mismo terreno escolástico, Servio Danielino vuelve sobre los pasos de los poetas, puesto que coloca a Alcestis como un exemplum: al comentar Aen. 4.468, afirma que "suelen extrañar a los suyos quienes perecen, como Alcestis cuando muere" (solent enim qui deficiunt suos desiderare, ut Alcestis moriens). Un lugar especial en este breve recorrido está reservado a los mitógrafos Higino y Fulgencio. El primero trata en varias de sus fabulae el mito; el segundo, en cambio, le da una interpretación alegórica, donde las figuras de Apolo y Heracles simbolizan la sabiduría y la virtud, respectivamente. El caso de Higino es especial porque nos da un panorama completo del mito, tal como podemos leer en las fabulae 50 y 51 : 
1. Después de haber requerido muchos en matrimonio a Alcestis, hija de Pelias, y tras haber rechazado éste a muchos pretendientes, les impuso una prueba: se la daría a quien unciera unas bestias salvajes a un carro. Y éste se la llevaría en ellas cuando quisiera. 2. Así pues, Admeto pidió a Apolo que le prestara ayuda. Apolo, habiendo sido tratado generosamente por aquél cuando se puso a su servicio, le proporcionó uncidos un jabalí y un león merced a los cuales Admeto condujo a Alcestis al carro.

\section{ALCESTIS}

1. Muchos pretendientes habían requerido en matrimonio a Alcestis, hija de Pelias y de Anaxibia, hija de Biante. Pelias, tratando de evitar sus propuestas, los fue rechazando y les impuso una prueba: se la daría a quien unciera unas bestias salvajes a un carro y se llevara a Alcestis en el carro. 2. Así pues, Admeto pidió a Apolo que le prestara ayuda. El dios, puesto que había sido tratado generosamente por él mientras estuvo a su servicio, le entregó uncidos un jabalí y un león con los que Admeto se llevó a Alcestis. 3. También recibió de Apolo el privilegio de que otro muriera voluntariamente en su lugar. Al no haber querido morir por él ni su padre ni su madre, su esposa Alcestis se ofreció y murió por él, reemplazándole en la muerte. Después Hércules la rescató de los Infiernos. ${ }^{5}$

Finalmente, nos detendremos en la mencionada Alcestis Barcinonensis, poema anónimo de 122 hexámetros, conservado en un papiro misceláneo $(\mathrm{P})$ perteneciente al siglo IV, y publicado por primera vez en Barcelona por Roca-Puig (1982). De género discutible, aunque creemos que tiene la forma de un epyllion, el texto puede dividirse, según Moreno Soldevila (2011), en las siguientes partes: 1) Plegaria de Admeto a Apolo y respuesta del oráculo (1-20); 2) vuelta de Admeto a su casa (21-22) y búsqueda de la victima vicaria: se producen los diálogos con el padre (23-42), la madre (43-70) y la esposa, Alcestis, única que accede a morir en su lugar (71-102), incluso sin que él se lo pida; 3) Preparación de los funerales y muerte de Alcestis (103-122). La comparación entre esta obra y la Alcesta centonaria es obligada y fue realizada por McGill (2005: 88-89, n.73), quien concluye que la principal semejanza entre ambas es que Alcestis logrará, paradójicamente, la vida eterna a través de la muerte, mientras que la diferencia central radica en el tema del nuevo

\footnotetext{
${ }^{5}$ ADMETVS. Alcestim Pel<iae> filiam cum complures in coniugium peterent et Pelias cum multos eorum repudiaret, simultatem his constituit, ei se daturum qui feras bestias ad currum iunxisset: [is quam uellet aueheret]. itaque Admetus ab Apolline petiit ut se adiuuaret. Apollo cum ab eo esset liberaliter tractatus cum in seruitium fuit ei traditus, aprum et leonem ei iunctos tradidit, quibus ille Alcestim in coniugium auexit. ALCESTIS. Alcestim Peliae et Anax $<$ i $>$ bies $<$ Bian $>$ tis filiae filiam complures proci petebant in coniugium; Pelias uitans eorum condiciones repudiauit et simultatem constituit, ei se daturum qui feras bestias ad currum iunxisset et Alcestim in coniugio auexisset. itaque Admetus ab Apolline petiit ut se adiuuaret. Apollo autem quod ab eo in seruitut<e $>$ liberaliter esset acceptus, aprum et leonem ei iunctos tradidit, quibus ille Alcestim auexit. et illud ab Apolline accepit, ut pro se alius uoluntarie moreretur. pro quo cum neque pater neque mater mori uoluisset, uxor se Alcestis obtulit et pro eo uicaria morte interiit; quam postea Hercules ab inferis reuocauit.

No sólo en estas dos fabulae Higino alude al mito. Cfr. Fab. 14, 24, 49, 97, 173, 243, 251 y 256. Trad. de DEL HOYO y GARCÍA RUIZ (2009: 137-8).
} 
matrimonio: el centón sigue la versión tradicional por la cual Alcestis le pide a Admeto que no se case de nuevo, en cambio la $A B$ contiene la variante mítica de que, siempre y cuando él la recuerde, Admeto puede volver a contraer matrimonio. Además, ambos poemas presentan la amistad de Apolo y Admeto, las referencias a los dioses infernales, la descripción de los síntomas de la muerte cercana y el lamento final. Como veremos en nuestro análisis, es difícil aceptar una postura como la de Markovich (1984: 114), que afirma: "But what a difference between the Alcesta of the $\mathrm{A}$ [nthologia] L[atina] and our Alcestis [AB]! The former is basically a Vergilian cento, while the latter is the product of an inspired, skilled and learned poet. To quote again my Oxford colleagues: 'Alcesta...: a flaccid pastiche which points up the merits of the Barcelona bard'". Si uno lee este párrafo, parece que la $A B$ hubiera sido escrita por un poeta extraordinario y que la Alcesta fuera el fruto de un dilettante trasnochado. No es ni una cosa ni la otra. En todo caso, como dice McGill (2005: 88), "the Alcestis Barcinonensis, while not a cento, is at least to some extent derivative, retelling as it does a conventional story and imitating as it does many models. The cento Alcesta, meanwhile, is simply derivative in a more ludic and radical way than the Barcinonensis".

\section{ALCESTA CENTONARIA: UNA NUEVA PERSPECTIVA DEL MITO}

La división estructural ofrecida por Paolucci (2014b) nos servirá de resumen del texto centonario:

Proemio (1-3): se enuncia la temática del centón (la historia de Admeto y su boda) y se invoca a Apolo.

Presentación de los antecedentes (4-44): El rey Pelias tenía una hija de una belleza extraordinaria, Alcestis, que era pretendida por numerosos jóvenes; sin embargo, Pelias había dispuesto una serie de pruebas que el futuro cónyuge debía superar (ponerles el yugo a un león y a un jabalí). Admeto acepta el desafío y se dirige al bosque, donde suplica la ayuda de Apolo, quien desciende del cielo para animarlo y prometerle su favor. Finalmente, el joven supera las pruebas, notablemente auxiliado por el dios, y se dirige al palacio, donde el rey cumple su promesa y entrega a su hija a su nuevo yerno.

1) Sentencia de las Parcas y diálogo con Apolo (45-84): luego de un tiempo, las Parcas determinan que al joven le ha llegado la hora funesta de la muerte; es precisamente Apolo el encargado de comunicarle la cruel noticia. Ante las palabras del dios, Admeto le suplica algún tipo de piedad, y Apolo le responde, en lenguaje oracular, que las leyes divinas prescriben que, para salvarse, otro debe morir en su lugar, es decir, debe buscar una victima 
vicaria. Admeto se dirige primero a Feres, su padre, para intentar que muera en su lugar, aprovechando su avanzada edad, pero el rey se rehúsa y le dice que Apolo lo engañó, porque cada cual tiene su día ya fijado.

2) Devotio de Alcestis (85-113): ante la negativa del rey, Admeto regresa llorando. Aparece por fin en escena Alcestis, que escucha los gemidos de su esposo y se acerca a preguntarle qué ocurría. Admeto se queja de tener que romper el silencio para contarle algo terrible y finalmente le refiere su situación. El verso 100, con el famoso primer verso del libro IV de la Eneida "pero la reina, ya atormentada por una profunda pena" (at regina gravi iamdudum saucia cura), marca el comienzo de la devotio de Alcestis y el tono del final del poema. Alcestis se ofrece a morir en lugar de su esposo

3) Muerte de Alcestis (114-162): con un discurso de profundo patetismo y altruísmo, Alcestis se despide de su esposo, rogándole conservar casto el lecho nupcial y evitarles así una madrastra a sus hijos, quienes estaban aferrados a ella mientras moría. Admeto le dirige un último discurso entre lágrimas, cuando Hermes viene a buscarla. Alcestis, finalmente, se despide y el último verso describe su muerte: "el calor se disipó y la vida desapareció en el viento" (dilapsus calor atque in ventos vita recessit).

Uno de los elementos más atractivos de este centón es su originalidad con respecto a la tragedia de Eurípides, que ya se puede apreciar en los primeros versos centonarios, cuando se menciona la competencia sancionada por Pelias para elegir a uno de los pretendientes como esposo de la princesa. Pero, indudablemente, el punto máximo de distanciamiento con respecto a la versión euripídea se produce en el final del poema, cuando se niega la resurrección de Alcestis: de esta manera, el centón recoge la versión más pesimista del mito, en la que la princesa muere sin que Heracles pueda buscarla en el Hades y "resucitarla". Por lo tanto, el centón centra todo el interés en Alcestis, la única verdadera protagonista, haciendo del mito una verdadera tragedia, a diferencia de lo que ocurre en Eurípides.

El carácter trágico del poema queda expuesto en la última sección, donde se hace notable la presencia de algunos versos representativos del libro IV de la Eneida con la clara intención de asignar a Dido un papel de "guía intertextual" del centónEste rasgo de romanitas que adquiere el mito puede verse claramente en los versos 125 a 128, correspondientes a una parte del discurso de Alcestis a su marido en la última sección del poema:

o dulcis coniunx, I castum servare cubile | 125

sis memor; I extremum hoc munus morientis habeto, I 
si bene quid de te merui, | lectumque iugalem |

natis parce tuis. I sic, sic iuvat ire sub umbras. I

"Oh dulce esposo, recuerda conservar casto el lecho, cumple este postrer deber a quien muere: si algo bueno merecí de tu parte, evita un lecho nupcial a tus hijos. Así, así, me agrada ir a las sombras".

125 Aen. 2.777+Aen. $8.412 \quad 126$ Aen. $12.439+$ Buc. 8.60

Aen. 4.317+Aen. 4.496128 Aen. 10.532+Aen.4.660

El primer hemistiquio o dulcis coniunx pertenece al libro II de la Eneida, cuyo contexto es el relato que Eneas hace a Dido en Cartago:

quaerenti et tectis urbis sine fine ruenti

infelix simulacrum atque ipsius umbra Creusae

visa mihi ante oculos et nota maior imago.

obstipui, steteruntque comae et vox faucibus haesit.

tum sic adfari et curas his demere dictis:

'quid tantum insano iuuat indulgere dolori,

o dulcis coniunx? non haec sine numine divum

eveniunt;

(...)

illic res laetae regnumque et regia coniunx

parta tibi; lacrimas dilectae pelle Creusae.

(...)

iamque vale et nati serva communis amorem.'

(Aen. 2.771-789)

\begin{abstract}
"Mientras buscaba y corría sin parar por las casas de la ciudad, apareció ante mis ojos el espectro de la misma Creúsa, su desafortunada figura, una imagen más grande que la que conocía. Me quedé paralizado, se erizaron mis cabellos y se me hizo un nudo en la garganta. Entonces habló así y con estas palabras alejó mis preocupaciones: ¿¿De qué te sirve abandonarte así a un dolor insensato, oh dulce esposo? Estas cosas no suceden sin la voluntad de los dioses. (...) Ahí las cosas te irán bien y encontrarás un reino y una esposa real; deja de llorar por tu querida Creúsa. (...) Adiós, entonces, y conserva el amor de nuestro hijo en común’”.
\end{abstract}

o dulcis coniunx es uno de esos hemistiquios problemáticos, porque está repetido en el v. 118 del centón, motivo para que la crítica considere este tipo de obras de poco valor. A nuestro entender, la repetición tiene un sentido mucho más profundo para la interpretación del texto, ya que uno podría preguntarse qué otro pasaje del corpus virgiliano podría acomodarse tan bien como este a esta sección del centón. La respuesta es "varios pasajes"6. Por ejemplo, sin ir tan lejos en el corpus, en el mismo libro (2.519) encontramos la expresión miserrime coniunx de Hécuba hacia Príamo, cuando el anciano, viendo su Troya arrasada, se pone las 
armas para combatir. Las palabras de Hécuba son un llamado a la sensatez para que el senex permanezca con ella. Por lo tanto, la elección de o dulcis coniunx no es arbitraria. La sección de Aen. 2.745-775 describe la afanosa búsqueda de Creúsa por parte de Eneas, que se cierra con los versos citados, donde la desesperación del héroe (v. 771) se topa con el espíritu de su esposa, que es descrita como infelix por Eneas. Servio comenta "mihi, non sibi", es decir, Creúsa es "desgraciada, infeliz" para Eneas, no para ella: el adjetivo se aplica a lo que siente Eneas acerca de su esposa. Esta es la primera pista importante para entender la relación con Alcestis, quien también es desdichada pero en el sentimiento de Admeto. La segunda pista es la expresión nota maior imago (v. 773), que remite a la idea de que los muertos adquieren un tamaño sobrehumano, pero aquí, como afirma Austin (1964: ad.loc), quizá también implica la noción de apoteosis, que se vincula con Alcestis en el sentido de que su muerte le garantiza una "deificación moral" dentro del mundo romano. Eneas queda paralizado ante el espectro pero Creúsa lo tranquiliza, con palabras que el centonarius seguramente pretendía que su lector tuviera en cuenta porque relacionan directamente a Creúsa con Alcestis. Sin embargo, aunque el sentido de ambos textos sea el de tranquilizar al marido, las implicancias y circunstancias de la muerte no tienen el mismo valor: mientras que Alcestis decide morir voluntariamente, la muerte de Creúsa es forzada por los hados, como ella misma dice: "estas cosas no pasan sin la voluntad de los dioses”. Pero la decisión de inmolarse por su esposo le permite a Alcestis pedirle a Admeto algo que Creúsa sabe que será imposible evitar en el caso de Eneas: el nuevo matrimonio. Creúsa explícitamente afirma que Eneas encontrará una nueva esposa, porque ese es su fatum, es el numen divum, mientras que Alcestis explícitamente le pide a Admeto el munus, el deber de no casarse de nuevo.

Por otra parte, no debe interpretarse el discurso de Creúsa como despreocupado (la profunda emoción que la embarga se evidencia en la interjección $o$ que precede el vocativo) sino más bien obligado porque es el fatum quien manda. Dentro de lo poco que puede hacer, se enfatiza su virtus y su carácter de matrona romana y pia coniunx, sobre todo cuando le encomienda a Eneas el cuidado de Ascanio, de quien el héroe tiene que ser padre y madre a la vez, en una versión renovada de la pietas (Austin 1964: ad.loc.). A partir de este contexto, puede interpretarse que Admeto, como Eneas, será padre y madre a la vez, pero el énfasis de la univira está puesto en la prohibición de segundas nupcias para su esposo. Esto no la hace menos virtuosa, sino que el centonarius quiere remarcar las diferencias con el texto épico, donde el fatum controla los destinos de Eneas y su futuro matrimonio con Lavinia, mientras que en el centón son la voluntad y la virtud de Alcestis las que posibilitan su demanda. 
El segundo hemistiquio del v. 125 castum servare cubile proviene de Aen. 8.412:

\author{
cum femina primum, \\ cui tolerare colo vitam tenuique Minerua \\ impositum, cinerem et sopitos suscitat ignis \\ noctem addens operi, famulasque ad lumina longo \\ exercet penso, castum ut servare cubile \\ coniugis et possit parvos educere natos: \\ la hora temprana en que la mujer, a quien se ha impuesto tolerar una vida con la \\ rueca y la modesta Minerva, aviva las cenizas y los fuegos dormidos añadiendo la \\ noche a su tarea y pone a sus criadas a hilar el pesado trabajo bajo la lámpara, para \\ poder conservar casto el lecho del esposo y criar a sus hijos pequeños
}

Se trata del símil que compara la hora cuando Vulcano se levanta para observar el fraguado de las armas de los troyanos con el momento en que la matrona casta comienza su tarea del hilado. Aunque el símil tiene antecedentes en Homero y Apolonio Rodio ${ }^{7}$, nada es más romano que la imagen de una matrona que hila a luz de un candil con sus famulae que la acompañan en la tarea. Como afirma Gransden (1976: ad.loc.), es el modelo de matrona univira, opuesta a la mujer oriental, en su devoción al hogar y la familia. Ubicado en el centro del libro más augusteo de la Eneida, quizá el símil refleja la importancia que el princeps daba a su legislación moral y matrimonial. Evidentemente, la inclusión de este hemistiquio en el centón se explica por sí misma, dado el contexto del nuevo texto: Alcestis es, claramente, una matrona romana, casta et pia.

El primer hemistiquio del v. 126, sis memor, pertenece al libro XII, las famosas palabras que Eneas dirige a Ascanio:
'disce, puer, virtutem ex me verumque laborem,
fortunam ex aliis. nunc te mea dextera bello
defensum dabit et magna inter praemia ducet.
tu facito, mox cum matura adoleverit aetas,
sis memor et te animo repetentem exempla tuorum
et pater Aeneas et avunculus excitet Hector.'
"Aprende, muchacho, el coraje y el esfuerzo verdadero; de otros, la fortuna. Ahora mi diestra en la guerra te dará defensa y te llevará entre grandes premios. Cuando luego te llegue la edad madura, acuérdate de esto y cuando busques en tu ánimo ejemplos de los tuyos, que te estimulen el padre Eneas y el tío Héctor".

Luego de que Eneas fuera curado de sus heridas, recoge sus armas y aconseja a Ascanio con estas palabras, que reflejan la importancia que tienen para el héroe el esfuerzo y el coraje, las dos virtudes heroicas elementales, según Borges, alejadas de la fortuna. La idea que está por detrás de este consejo es que cada uno, con esas virtudes, debe forjarse su

\footnotetext{
${ }^{7}$ Cf. Gransden (1976: ad.loc.) y Eden (1975: ad.loc.).
} 
destino. El valor de estas palabras puestas en boca de Eneas repercute en Alcestis, quien alcanza en este momento una dimensión heroica, pero, ante todo, se destaca el valor ejemplar que asume su decisión de morir por su esposo, algo que requiere virtutem verumque laborem.

El segundo hemistiquio del v. 126 corresponde a Buc. 8.60,

praeceps aerii specula de montis in undas /

deferar; extremum hoc munus morientis habeto,

desde la cima de un elevado monte me precipitaré en el mar; tendrás este postrer regalo del que muere

En este caso, sólo vamos a remarcar el nuevo significado que asume el término munus en el centón: mientras que en el contexto pastoril significa "regalo", para Alcestis significa “deber, tarea, obligación” que Admeto debe cumplir.

Por último, los vv. 127-128 están conformados por cuatro hemistiquios, de los cuales tres pertenecen al libro IV de Eneida. Por cuestiones de espacio, nos detendremos sólo en el análisis del segundo hemistiquio del v. 127, cuyo contexto es el siguiente:

\footnotetext{
tu secreta pyram tecto interiore sub auras erige, et arma viri thalamo quae fixa reliquit impius exuviasque omnis lectumque iugalem, quo perii, super imponas: abolere nefandi cuncta viri monimenta iuvat monstratque sacerdos

"Tú levanta en secreto una pira dentro del palacio al aire libre, y las armas del varón, que el impío dejó colgadas en el tálamo, todas las cosas que usó y el lecho conyugal, en el que me perdí, ponlos encima: me ayuda destruir todos los recuerdos de un hombre innombrable, y así lo dispone la sacerdotisa".

El pasaje nos muestra la orden de Dido a su hermana Ana para que construya la pira donde se debe destruir todo lo que tocó y dejó Eneas. Son versos cargados de sentido, tal como puede apreciarse con sólo comentar que el pius Aeneas acá se convierte en impius (un adjetivo usado en la Eneida, por ejemplo, para describir a Pigmalión). A pesar de que lectus es una palabra común, una unpoetisch Wort, indigna del género épico, Virgilio la introduce por su vínculo con lectus genialis, el término jurídico para el lecho nupcial, con lo que Dido quiere ratificar la legalidad de su matrimonio. Además, es notable que el término iugalis sea utilizado por primera vez por Catulo en el carmen 64, v. 302 taedas iugalis, que alude al matrimonio, también con consecuencias desgraciadas, entre Tetis y Peleo. Todas estas alusiones negativas se revierten en el centón para dar una imagen positiva, dentro de lo trágico de la temática, al lecho que compartían, legalmente, Admeto y Alcestis. Esa legalidad se refleja en que no habrá otra boda en el futuro, que es la única garantía que pide Alcestis 
para su sacrificio: el hemistiquio final es revelador de este optimismo por parte de la reina: sic, sic iuvat ire sub umbras ("así, así me agrada ir a las sombras").

Como conclusión, podemos apreciar de qué manera se produce la resemantización de los hemistiquios virgilianos en este nuevo contexto trágico del centón. En el pasaje seleccionado, la figura de Alcestis, protagonista excluyente de la obra, se vincula con tres personajes virgilianos: Creúsa, Eneas y Dido. Del héroe, Alcestis toma precisamente las virtudes que el propio Eneas aconseja a su hijo: el esfuerzo y el coraje, ambas presentes en la conmovedora decisión de Alcestis de ofrecer la vida por su marido. En los casos de Creúsa y Dido, la relación es más bien de diferencia, enfatizada por la notable habilidad del centonarius al lograr que los contextos situaciones sean similares. Creúsa, en su reclamo a Eneas para que este cuide de sus hijos, se presenta como un espectro víctima del fatum, cuya muerte es involuntaria, a diferencia de Alcestis quien, como heroína, logra controlar su propio destino, según el consejo de Eneas a Ascanio. En cuanto a Dido, el vínculo se produce en el contexto general de tragedia que es el libro IV, con la reina de Cartago como figura central, pero Alcestis y Dido también presentan profundas diferencias, sobre todo, en este pasaje, en relación con el modo de definir sus vínculos conyugales: mientras que Dido nunca llega a asumir que su lazo con Eneas no es más que un furtivus amor, sin una base legal -en términos romanos-, el matrimonio entre Alcestis y Admeto es perfectamente de derecho, a tal punto que le permite a la reina solicitar a su marido la prohibición de futuras nupcias.

En definitiva, el análisis de esta mínima sección del poema centonario demuestra que la resignificación de los versos virgilianos implica una novedosa caracterización de Alcestis, que simboliza en el texto todas las virtudes de una matrona romana, sobre todo, la pietas coniugale: se presenta como una esposa ideal, matrona univira et pia, a diferencia de lo que se muestra en Eurípides. El centón representa los ideales de la más rígida paideia latina (pietas hacia el esposo, virtus, laus post mortem), con el típico pragmatismo ético de los romanos, para quienes el exemplum que se da es fundamental; ese exemplum está conformado por la generosidad, el altruísmo y el coraje, encarnados en Alcestis.

Para intentar definir qué tipo de intertextualidad opera en el centón, seguimos a Polara (1990), quien afirma que la alusión en este tipo de textos no funciona ni por metáfora ni por símil (según las categorías de Conte [1986]), sino que se trata de un tercer tipo, que podría definirse como "memoria poética por antanaclasis", una figura de repetición que consiste en hacer uso del valor polisémico de algunas palabras donde se repite el significante (o cuerpo fónico de la palabra) pero en cada aparición el significado es diferente. Este tipo tan 
particular de intertextualidad implica, por un lado, un conocimiento perfecto de la tradición literaria y mítica grecolatina y, por el otro, el desafío de la originalidad, término que aparecía en la historia de la crítica literaria no hace mucho tiempo atrás como un oxímoron de la tipología del centón. En contra de la opinión de sus detractores, la Alcesta centonaria demuestra que su autor tenía no sólo un amplio dominio literario y mítico -el modo como adapta el verso virgiliano es una muestra de cómo la misma obra virgiliana, en este caso la Eneida, fue sometida a un análisis interno de sus personajes, contextos y situaciones- sino también, y mucho más importante, plena conciencia de la nueva perspectiva del mito de Alcestis -su romanitas- que es, en definitiva, la marca de su originalidad. 


\section{BIBLIOGRAFÍA}

\section{Fuentes Primarias}

CONTE, Gian Biagio. P. Vergilius Maro: Aeneis. De Gruyter, Berlin, 2009.

DEL HOYO, Javier; GARCÍA RUIZ, José Miguel. Higinio, Fábulas. Gredos, Madrid, 2009. RIESE, Alexander. Anthologia Latina I.1, Leipzig, $1894^{2}$.

ROCA-PUIG, Ramón. Alcestis. Hexàmetres Llatins. Papyri Barcinonenses, Inv. n. 158-161. Barcelona, 1982.

SALANITRO, Giovanni. Alcesta, Cento Vergilianus. Bonanno, Roma, 2007.

\section{Fuentes Secundarias}

AUSTIN, Roland (1964). P. Vergili Maronis Aeneidos Liber Secundus. Oxford University Press, Oxford.

CONTE, Gian Biagio (1986). The Rhetoric of Imitation. Genre and Poetic Memory in Virgil and other Poets. Cornell University Press. Ithaca and London.

DOWDEN, Ken (2000). "Alcestis" in HORNBLOWER, Simon and SPAWFORTH, Antony, The Oxford Classical Dictionary, Oxford University Press, Oxford.

EDEN, P. T. (1976). Commentary on Virgil: Aeneid VIII, Brill, Leiden.

GRANSDEN, Ken. (1976). Virgil: Aeneid Book VIII, Cambridge University Press, Cambridge.

LAMACCHIA, R. (1984), “Centones”, en Enciclopedia Vergiliana, Vol I, Roma, pp.733737.

LAMACCHIA, Rosa (1958), “Dall' arte allusiva al centone”, $A \& R$, Roma, 3, pp. 193-216.

MARKOVICH, Miroslav (1984), “Alcestis Barcinonensis”, ICS, Illinois, 9.1, pp. 111-134.

MCGILL, Scott (2005), Virgil Recomposed. The Mythological and Secular Centos in Antiquity, Oxford University Press, Oxford.

MORENO SOLDEVILA, Rosario (2011), "El motivo del lecho conyugal en la Alcestis Barcinonensis: dos notas de lectura", Emerita, Madrid, LXXIX 1, pp. 177-188.

PAOLUCCI, Paola (2006). Il centone virgiliano Hippodamia dell'Anthologia Latina: Introduzione, edizione critica, traduzione e commento, Georg Olms, Hildesheim. 
PAOLUCCI, Paola (2014a). "Alcesti greca, Alcesti latina, Alcesti cristiana" in PAOLUCCI, P. Studi sull'Alcesta centonaria, Morlacchi, Perugia, pp. 11-48.

PAOLUCCI, Paola (2014b). "Il genus mixtum dell'Alcesta centonaria" in PAOLUCCI, P. Studi sull'Alcesta centonaria, Morlacchi, Perugia, pp. 49-65.

POLARA, Giovanni (1990). "I centoni'" in CAVALLO, G., FEDELI, P. y GIARDINA, A., Lo spazio letterario di Roma antica, ed. 5 vols., Salerno, Roma, vol. 3, pp. 245-275.

SALANITRO, G. (1997), "Osidio Geta e la poesia centonaria", New York-Berlin, ANRW 2.34.3, pp. 2336-2356. 